\title{
Nucleate boiling flow - experimental investigations and wall heat flux modelling for automotive engine applications
}

\author{
H. Steiner ${ }^{1}$, B. Breitschädel ${ }^{2}$, G. Brenn ${ }^{1}$, H. Petutschnig ${ }^{3}$ \\ \& C. Samhaber ${ }^{4}$ \\ ${ }^{1}$ Institute of Fluid Mechanics and Heat Transfer, \\ Graz University of Technology, Austria \\ ${ }^{2}$ Competence Center "The Virtual Vehicle" (vif) Graz, Austria \\ ${ }^{3}$ AVL LIST GmbH Graz, Austria \\ ${ }^{4}$ BMW Motoren GmbH Steyr, Austria
}

\begin{abstract}
In the continuing search for highly efficient technical cooling devices, the nucleate flow boiling regime is becoming increasingly appreciated for providing the highest possible heat transfer rates. Regarding the case of liquid cooling systems of combustion engines, it is known that subcooled boiling occurs in thermally highly loaded regions. Therefore, reliable thermal management requires sufficient knowledge on how specific operation conditions and system parameters typically found in engine cooling jackets can affect the subcooled boiling heat transfer. In particular, the present work investigates experimentally the effects of varying volume fractions of the two main components of the coolant, of varying roughness and orientation of the hot wall surface with respect to the vector of gravitational acceleration, and of vibrations of the hot surface. The obtained comprehensive data set is highly valuable to elucidate and quantify the impact of the investigated effects. The data are also used to evaluate the performance of a wall heat flux model, which was specially developed for use in subcooled boiling flow in automotive applications. The model is proven to provide good overall accuracy for the considered experimental conditions.
\end{abstract}

Keywords: subcooled boiling heat transfer, heated surface roughness, heated surface vibrations, heated surface orientation, liquid composition. 


\section{Introduction}

Wherever high thermal power has to be transferred across confined areas, the nucleate boiling flow represents an attractive regime for providing high heat transfer rates. The flow boiling heat transfer is therefore of great interest in various technical applications ranging from electronic chip cooling to high efficiency compact heat exchangers. The particular case of subcooled boiling flow, where nucleate boiling occurs only in a thin superheated near-wall layer, while the outer bulk liquid remains below saturation temperature, is also of great relevance in liquid cooling jackets of combustion engines, where it helps to keep the temperatures of the heated walls on acceptable levels. A more extensive use of the great potential of nucleate boiling requires a sufficient knowledge on how and to what extent specific system parameters and/or operation conditions may affect the nucleate boiling heat transfer. In particular, the present work experimentally investigated the effects of the composition of the working liquid, and the effects of the heated surface roughness, orientation and vibration. The comprehensive experimental data base obtained in these experiments is also highly valuable for the validation of the modelling of the wall heat flux. Accordingly, the present study assesses the accuracy and the limits of a typical ansatz known as Boiling-Departure-Liftoff (BDL) model, which has become a well-established approach for the modelling of the total wall heat flux with subcooled boiling in automotive coolant flow.

\section{Experimental setup}

The present experimental apparatus basically consists of a closed loop, where the flow is generated by a pump. The working fluid is preconditioned to enter the test section at a defined bulk temperature, velocity and operating pressure. The velocity of the bulk flow can be varied within the range of $0.05 \leq u_{b} \leq 2.0 \mathrm{~m} / \mathrm{s}$, corresponding to the range of Reynolds numbers between 2200 and 88000 . The absolute operating pressure can be set within the range $1.0 \leq \mathrm{p} \leq 2.0$ bar. The key part of the device, i.e. the test section, is schematically shown in fig. 1. It is basically a duct with a square-shaped cross section of dimensions $36 \times 36 \mathrm{~mm}^{2}$. The heat flux into the channel is generated by electric cartridge heaters (Bach Resistor Ceramics) located at the bottom of the aluminium heater, from where the heat is conducted to the top of the heater. At the upper surface, whose length is $65 \mathrm{~mm}$ and width is $10 \mathrm{~mm}$, the heat is transferred to the working fluid flowing through the channel. The wall temperature as well as the wall heat flux are determined based on measurements of the temperature using twelve K-type thermocouples appropriately distributed in the solid heater. The base plate of the test section, where the top of the aluminium heater is integrated, is made of Polytetrafluoroethylene (PTFE), whose very low thermal conductivity $\left(\lambda_{\mathrm{PTFE}}=\right.$ $0.23 \mathrm{~W} / \mathrm{mK}$ ) should guarantee lowest possible heat losses from the heater to the surrounding structure. Due to thermal durability restrictions of the PTFE base plate, the maximum heater surface temperature was limited to $T_{w}=160^{\circ} \mathrm{C}$. Glass 
windows are embedded in the three unheated walls of the test section to make the section optically accessible. For the investigation of the effect of the orientation of the heated surface with respect to the direction of the gravitation force the whole test section could be rotated around the channel axis by a prescribed angle $\kappa$. The rotation of the test section was possible while the system remained filled with liquid, so that the heater surface was always wetted to ensure good reproducibility of the results. When investigating the effect of heated surface vibration, the bottom of the aluminium heater was connected to the actuator head of an electro-dynamic shaker (Brüel and Kjaer $45 \mathrm{~N}$ ) to excite a predefined oscillatory motion of the heater. The oscillatory motion was optically recorded with a laser vibrometer.

Using the present experimental setup, errors in the experimentally obtained heat fluxes are mainly due to measurement and position errors of the thermocouples, as well as the uncertainties in the actual thermal conductivity of the heater material (aluminium alloy) and in the heat losses to the surroundings of the heater. A worst-case estimation yielded a total error of the heat flux ranging from $\pm 5 \%$ in the convective regime to $\pm 2 \%$ in the nucleate boiling regime, always referring to the value actually obtained from the measurements. The error in the measured surface temperatures amounts to $\pm 0.15^{\circ} \mathrm{C}$. The inductive flow meter measures the flow rate with a relative error as low as $\pm 0.5 \%$ of the displayed value.

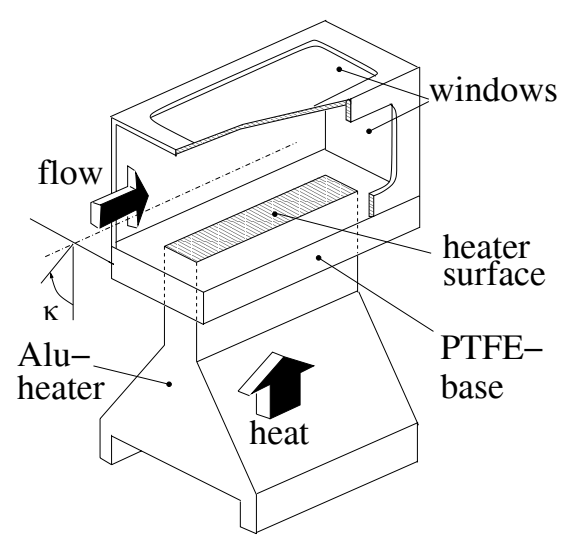

Figure 1: Experimental test section.

\section{Examined model for the total wall heat flux}

The present work considers the so-called Boiling-Departure-Lift-off (BDL) model, which is basically a linear superposition approach originally introduced by Chen [1]. As such the BDL model assumes the total wall heat flux $\mathrm{q}_{\mathrm{w}}$ to be composed of a convective ( $\left.\mathrm{q}_{\text {conv }}\right)$ and a nucleate boiling contribution $\left(\mathrm{q}_{\mathrm{nb}}\right)$ 


$$
\mathrm{q}_{\mathrm{w}}=\mathrm{q}_{\text {conv }} \mathrm{F}+\mathrm{q}_{\mathrm{nb}} \mathrm{S} .
$$

The convective component $\mathrm{q}_{\mathrm{conv}}$ is obtained from the Dittus-Boelter correlation for forced convective channel flows. The factor $\mathrm{F}$ represents the enhancement of the convective component due to the bubble agitation. Since in subcooled boiling flow the vapour fractions are generally low, it is argued that this effect is negligible, assuming $\mathrm{F}=1$. The nucleate boiling component $\mathrm{q}_{\mathrm{nb}}$ is obtained from a classical pool boiling correlation due to Forster and Zuber [2]. The factor $\mathrm{S}$ is introduced to reflect the suppression of nucleate boiling observed at increasing flow rates. The BDL approach models $\mathrm{S}$ based on a balance of forces acting on the vapour bubbles at the instants of their detachment and liftoff from the heated surface. As such, S is obtained as essentially dependent on the near-wall velocity field. $\mathrm{S}$ is unity in the reference case of pool boiling with zero flow velocity, and it decreases to zero, $\mathrm{S} \rightarrow 0$, as the bulk flow velocity becomes higher.

The BDL model was originally devised and calibrated for subcooled boiling in automotive engine coolant flow in automotive engines (Kobor [3]). It was later extended to boiling with pure water by Steiner et al. [4], where a detailed formulation of the model equations is given. The BDL model has become a wellestablished approach especially in the automotive industry. The accuracy of the BDL model shall be assessed using the original set of the model coefficients of Kobor [3] when applied to the coolant flow under the particular conditions investigated in the experiments.

\section{Results for the investigated effects}

The baseline experimental conditions of the present investigations were specified to meet typical operating conditions in automotive liquid cooling systems. Following this premise, the temperature of the bulk liquid at the inlet of the test section was always set to $T_{b}=95^{\circ} \mathrm{C}$, and the absolute pressure of the system was was varied within $1.2 \leq \mathrm{p} \leq 2.0$ bar. The wall heat flux varied within the range $0 \leq \mathrm{q}_{\mathrm{w}} \leq 0.5 \mathrm{MW} / \mathrm{m}^{2}$, yielding wall superheats up to $\Delta \mathrm{T}_{\mathrm{sat}}=\mathrm{T}_{\mathrm{w}}-\mathrm{T}_{\mathrm{sat}}=40 \mathrm{~K}$. The considered velocities of the bulk liquid were chosen within $0.05 \leq \mathrm{u}_{b} \leq 0.5 \mathrm{~m} / \mathrm{s}$.

\subsection{Composition of the liquid}

The considered working liquid basically consists of two main components, deionized water and glysantin G48 from BASF. The latter basically consists of ethylene-glycol and additives, which represents a typical antifreeze component of engine coolants and is widely used in the automotive industry. The present experiments investigated the effect of the binary composition by considering three volumetric mixing ratios, $40 / 60,50 / 50$, and $60 / 40 \mathrm{vol} \%$ glysantin/water, respectively.

Two sets of flow boiling curves, which were experimentally measured for the three considered mixtures at the Reynolds numbers $\mathrm{Re}_{\mathrm{b}}=5500$ and 22000, are 
shown in figs. 2a und b, respectively. The bulk velocities corresponding to the two Reynolds number are about $\mathrm{u}_{\mathrm{b}}=0.1$ and $0.4 \mathrm{~m} / \mathrm{s}$, respectively. It becomes obvious that in both cases the $60 / 40 \mathrm{Vol} \%$ mixture, i.e., the liquid with the smallest fraction of the more volatile component (water), exhibits the lowest total wall heat fluxes at a given wall superheat $\Delta \mathrm{T}_{\text {sat }}>0$ in the nucleate boiling regime. This observation is confirmed by previous studies with binary and ternary systems in literature (Kandlikar [5], Wenzel et al. [6]), who attributed the observed tendency to a basically non-azeotropic behaviour of the mixture: the fraction of the more volatile component decreases faster in the liquid next to the bubble surface, which increases the effective saturation temperature of the local mixture being enriched with the less volatile component. The boiling curves obtained with the BDL model, also shown in figs. 2a,b, exhibit the experimentally observed tendency as well, even though the predicted heat flux levels are generally somewhat too low. Nonetheless, it is evidently sufficient to model the effect of the varying glysatin/water ratio in terms of a corresponding variation of the material properties of the mixture, which basically means assuming the binary system as an azeotropic mixture, as it is done in the BDL model. The model neglects any non-azeotropic effects, and it computes the material properties based on phase and thermodynamic equilibrium assumptions for a given mixture.

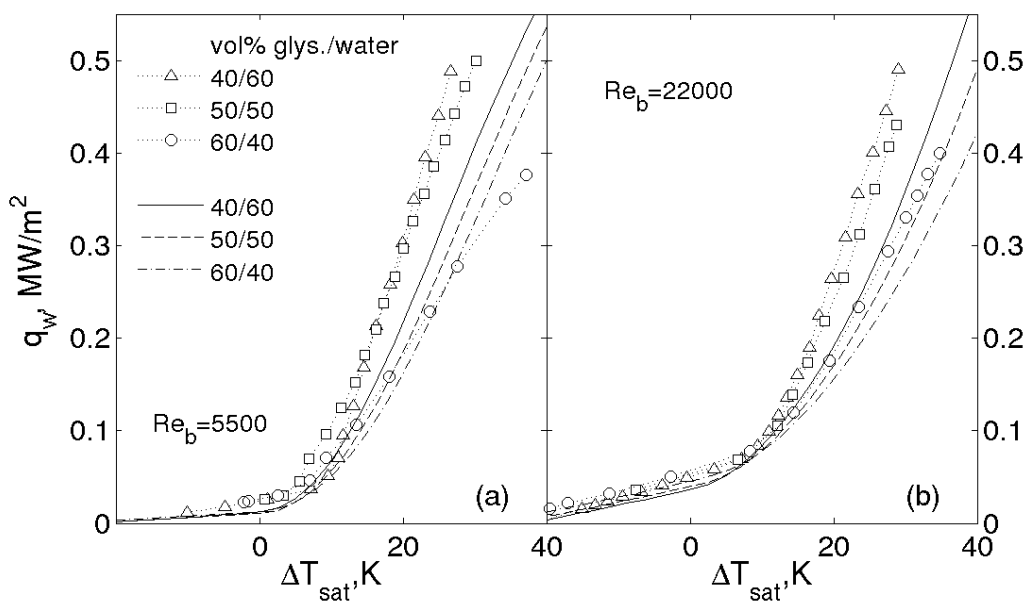

Figure 2: Flow boiling curves for varying coolant compositions: (a) $\mathrm{Re}_{\mathrm{b}}=5500$; (b) $\mathrm{Re}_{\mathrm{b}}=22000$; experimental data denoted by symbols, BDL model predictions by lines; pressure: $p=1.5$ bar.

\subsection{Roughness of the heated surface}

It is generally accepted that surface roughness can increase the boiling heat transfer rates only if the roughness elements provide additional active nucleation sites. To remain active they must be capable to trap a gaseous rest after bubble 
detachment to provide a nucleus for the formation of the next bubble. Thus, the initial effect of surface roughness may finally vanish due to a successive flooding of active cavities and/or a long-term change of the surface microstructure caused by corrosion or deposition of solids from the liquid (these processes are frequently subsumed as "aging"). Such a levelling down of primary roughness effects was already observed in an early work by Jakob and Fritz [7] for boiling of water on copper plates with different surface finish. The present experimental investigations consider three types of surface roughness, whose mean $\left(R_{z}\right)$ and maximum $\left(R_{\max }\right)$ peak-to-valley roughness heights are listed in tab. 1 .

Table 1: $\quad$ Roughness heights of heated surface types.

\begin{tabular}{|l|c|c|}
\hline \multicolumn{1}{|c|}{ Surface } & $\mathrm{R}_{\mathrm{z}}, \mu \mathrm{m}$ & $\mathrm{R}_{\max }, \mu \mathrm{m}$ \\
\hline Aluminium as cast: 'standard' & 45.7 & 51.7 \\
\hline Aluminium as cast: 'rough' & 130 & 143 \\
\hline Aluminium polished: 'smooth' & 1.99 & 2.38 \\
\hline
\end{tabular}

The first surface termed 'standard' matches the surface characteristics of the cast aluminium material commonly used for automotive cylinder heads. As such, it represents a reference case. The second surface termed 'rough' was produced by sand casting, using very coarse grains leading to big superficial cavities. The third surface termed 'smooth' is originally a sand casted standard surface, which has been milled and polished. The experimentally measured flow boiling curves, as obtained after increasing operation time, are shown in fig. 3 .

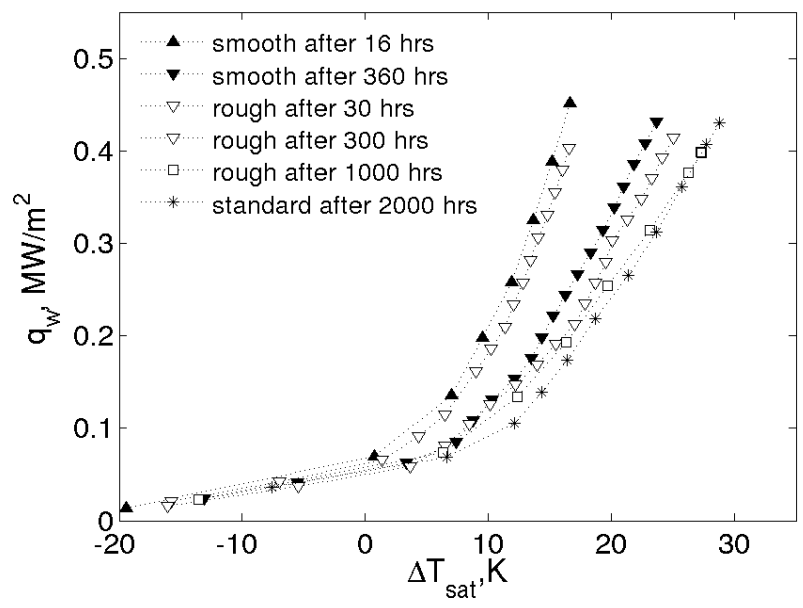

Figure 3: $\quad$ Flow boiling curves for varying surface roughness after different operation times; velocity of the bulk liquid $\mathrm{u}_{\mathrm{b}}=0.476 \mathrm{~m} / \mathrm{s}$; mixture $50 / 50 \mathrm{Vol} \%$ glysantin/water, pressure $\mathrm{p}=1.5 \mathrm{bar}$. 
It is seen that both the smooth and the rough surfaces exhibit almost the same heat transfer conditions at a primary stage, since the earliest measured boiling curves of both surfaces almost coincide. The considerable concentration of large cavities on the very rough surface evidently does not provide additional active nucleation centres compared to the smooth polished surface. With increasing operation time, both types of surfaces exhibit a notable degradation of the heat transfer rate, as seen from the shift of the boiling branches towards higher wall superheats. They finally approach the boiling curve of a long-term measurement using the standard surface. The present results are evidently well in line with the aforementioned observations of other authors in literature: the aging related changes of the microgeometry during long-term operation level out any potential primary surface roughness effect on the boiling heat transfer. For the presently considered surface types the effect of surface roughness can be therefore neglected. Accordingly, it need not to be explicitely considered in the modelling of the wall heat flux either.

\subsection{Orientation of the heated surface}

Due to the large liquid/vapour density ratio, buoyancy, and hence the orientation of the heated surface with respect to the gravitational vector, may strongly influence the bubble dynamics in boiling flow. The present work investigated in particular three cases of the surface orientation, an upward facing surface heated from below, representing the reference case, a horizontally sideward facing surface heated from aside, and a downward facing surface heated from above. The flow boiling curves measured for different velocities of the bulk liquid $u_{b}$ did not differ notably for the upward and the sideward facing cases. Contrarily, the downward facing case exhibited a rapid increase of the wall superheats at certain wall heat fluxes in the low velocity range, as it is seen in figs. 4a-c. The optical observation of the conditions on the heated surface clearly attributes this critical decrease of the wall heat transfer rate to significant bubble agglomeration leading to the formation partial vapour films. Based on a dimensional analysis, a criterion for the observed transition from nucleate to partial film boiling was derived in terms of the non-dimensional correlation

$$
\mathrm{Bo}_{\text {trans }}=\mathrm{CRe}_{\mathrm{L}} \mathrm{Ec}_{\text {sub }}^{-\mathrm{n}} \text {. }
$$

This correlation involves the Boiling number $\mathrm{Bo}_{\text {trans }}=\mathrm{q}_{\mathrm{w}, \text { trans }} / \mathrm{u}_{\mathrm{b}} \rho_{\mathrm{l}} \mathrm{h}_{\mathrm{lg}}$, the Reynolds number $\mathrm{Re}=\mathrm{u}_{\mathrm{b}} \rho_{\mathrm{l}} \mathrm{L} / \eta_{1}$ with the length scale $\mathrm{L}=\left[\sigma_{\mathrm{lg}} / \mathrm{g}\left(\rho_{\mathrm{l}}-\rho_{\mathrm{g}}\right)\right]^{0.5}$, and the Eckert number $\mathrm{Ec}_{\mathrm{sub}}=\mathrm{u}_{\mathrm{b}}{ }^{2} / \mathrm{c}_{\mathrm{p}, 1}\left(\mathrm{~T}_{\mathrm{sat}}-\mathrm{T}_{\mathrm{b}}\right)$, where $\rho_{1}, \eta_{1}, \mathrm{c}_{\mathrm{p}, 1}$ are the density, dynamic viscosity, specific heat of the bulk liquid, respectively, $\sigma_{\lg }$ the surface tension, and $\mathrm{h}_{\mathrm{lg}}$ the latent heat. $\mathrm{C}=8.5 \cdot 10^{-11}$ and $\mathrm{n}=-0.63$ are empirically determined model parameters. As shown in figs. $4 \mathrm{a}-\mathrm{c}$ by the dumbbell-shape marks, the transitional heat fluxes $\mathrm{q}_{\mathrm{w} \text {,trans }}$ obtained from the correlation given in eq. (2) basically demarcate the transition from nucleate to partial film boiling. As such, they also represent a reliable upper limit for the applicability of the BDL model, whose predictions start to deviate significantly from measurements for wall heat fluxes $\mathrm{q}_{\mathrm{w}}$ exceeding $\mathrm{q}_{\mathrm{w} \text {,trans }}$ 


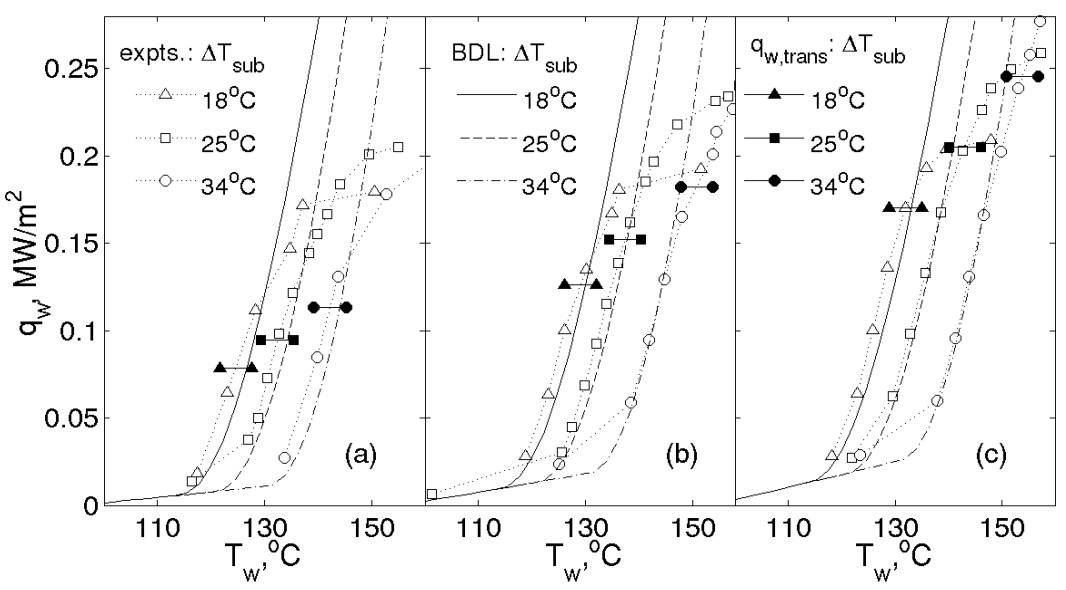

Figure 4: $\quad$ Flow boiling curves with downward facing surface for different subcoolings $\Delta \mathrm{T}_{\text {sub }}=\mathrm{T}_{\text {sat }}-\mathrm{T}_{\mathrm{b}}$ and varying velocities of the bulk liquid: (a) $\mathrm{u}_{\mathrm{b}}=0.05 \mathrm{~m} / \mathrm{s}$, (b) $\mathrm{u}_{\mathrm{b}}=0.095 \mathrm{~m} / \mathrm{s}$, (c) $\mathrm{u}_{\mathrm{b}}=0.142 \mathrm{~m} / \mathrm{s}$; mixture $50 / 50 \mathrm{Vol} \%$ glysantin/water, pressures for the three increasing subcoolings: $\mathrm{p}=1.2,1.5$ and 2.0 bar, respectively.

\subsection{Vibrations of the heated surface}

Previous studies in literature on the effect of heated surface vibrations on the heat transfer rate have mainly considered the pool boiling case (see, e.g., Bergles [8]). The present study considers flow boiling with vibrations of the heated surface typically occurring in automotive liquid cooling systems. The approximately sinusoidal surface motion, which is excited by the shaker in the experiments, is parameterized in terms of the frequency $f$ and the rms-velocity of the vertically oscillating surface

$$
\mathrm{V}_{\text {vib,rms }}=\left[\frac{1}{\tau} \int_{\mathrm{t}=\mathrm{t}_{0}}^{\mathrm{t}_{0}+\tau} \mathrm{v}_{\mathrm{vib}}^{2}(\mathrm{t}) \mathrm{dt}\right]^{1 / 2}, \tau \rightarrow \infty,
$$

with $\mathrm{V}_{\text {vib }}(\mathrm{t})$ obtained from the laser vibrometer. The investigated oscillation conditions are within the range of $0.0 \leq \mathrm{f} \leq 1000 \mathrm{~Hz}$ and $0 \leq \mathrm{v}_{\text {vib,rms }} \leq 0.02 \mathrm{~m} / \mathrm{s}$. The measurements for the considered oscillatory conditions revealed that the influence of the oscillations on the heat transfer is very small and that it is limited to very low velocities of the bulk. This is exemplarily shown in fig. 5a, where a somewhat higher heat transfer rate is observed at the higher wall heat fluxes in the oscillating case. Fig. 5b shows the results of more detailed measurements carried out at a fixed high and a low heat flux level, denoted $\mathrm{q}_{\mathrm{w}, \mathrm{H}}$ and $\mathrm{q}_{\mathrm{w}, \mathrm{L}}$, respectively, for varying frequencies and rms-vibration velocities. At the high heat flux, the wall temperatures tend to get a little bit lower as $\mathrm{v}_{\mathrm{vib}, \mathrm{rms}}$ increases, which indicates an increasing heat transfer rate. The low heat flux case shows the opposite tendency. Since the here observed quantitative variation of the wall superheat is still very small in both cases, it is concluded that, under the 
considered oscillatory conditions relevant in automotive cooling, the effect of surface vibrations on heat transfer is negligible. Hence, it need not be accounted for in the wall heat flux modelling either.
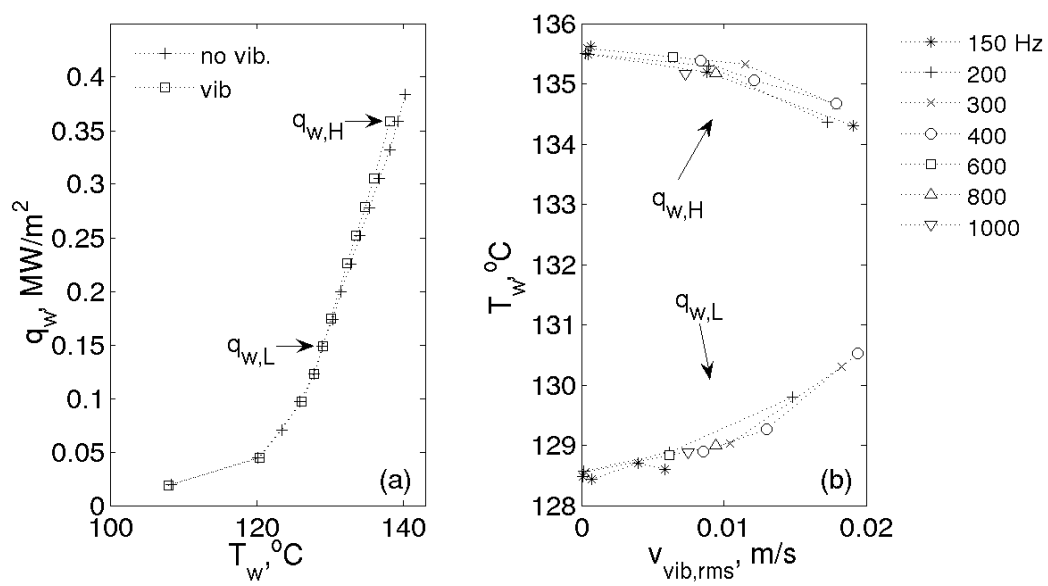

Figure 5: (a) Flow boiling curves with heated surface vibrations $(\mathrm{f}=200 \mathrm{~Hz}$, $\left.\mathrm{v}_{\text {vib,rms }}=0.015 \mathrm{~m} / \mathrm{s}\right)$ and without vibrations $\left(\mathrm{f}=0, \mathrm{v}_{\text {vib,rms }}=0\right.$ ); velocity of the bulk liquid $\mathrm{u}_{\mathrm{b}}=0.05 \mathrm{~m} / \mathrm{s}$; (b) wall temperatures at two wall heat fluxes $\mathrm{q}_{\mathrm{w}, \mathrm{H}}$ and $\mathrm{q}_{\mathrm{w}, \mathrm{L}}$ for varying oscillatory conditions (f, $\left.\mathrm{V}_{\mathrm{vib}, \mathrm{rms}}\right)$ of the surface; mixture $50 / 50 \mathrm{Vol} \%$ glysantin/water, pressure $\mathrm{p}=1.2$ bar.

\section{Conclusions}

The present study experimentally investigated various effects on the subcooled flow boiling which are of relevance in automotive liquid cooling systems, where the highly efficient flow boiling heat transfer is becoming increasingly important for a reliable and save thermal management. The measured data are also used to evaluate a popular approach for modelling the wall heat flux, known as the BDL model.

The investigations on the influence of the mixing ratio of the two main components of the coolant show that the heat transfer rates in the boiling regime tend to get lower when the fraction of the more volatile component is smaller. The tested wall heat flux model, which basically assumes the coolant as an azeotropic mixture, reflected the observed tendency very well. This suggests that the effect of the mixing ratio can be captured with sufficient accuracy in terms of the material properties of the mixture, neglecting non-azeotropic effects.

The relevance of the effect of the surface roughness turned out to be very limited in time. Long-term operation always produced a microstructure on the surface, which finally lead to approximately the same boiling behaviour of all investigated surface finishes. Based on this observation it is suggested to disregard the effect of the surface finish in terms of a roughness height in the wall heat flux model. 
The investigations of effects of the surface orientation demonstrated that, in the case of a downward facing surface heated from above, a transition from nucleate boiling to partial film boiling can occur at low velocities of the bulk liquid. A non-dimensional criterion is proposed to provide a reliable estimate for the wall heat fluxes, where the critical transition from nucleate boiling to partial film boiling has to be expected. Below the so estimated transitional wall heat fluxes, the BDL wall heat flux model showed good agreement with the experiments without any modifications to account for the effect of orientation.

For the considered oscillatory conditions relevant in automotive cooling systems, a very small effect of heated-surface vibrations on the flow boiling heat transfer was observed, occurring only at very low velocities close to the pool boiling limit. It is therefore practically negligible in the wall heat flux model as well.

\section{Acknowledgements}

Financial support of this work from the $\mathrm{K}$ plus Competence Center Program initiated by the Austrian Federal Ministry of Transport, Innovation, and Technology (BMVIT) and funded by FFG, Land Steiermark, and Steirische Wirtschaftsförderung (SFG) is gratefully acknowledged. We are also grateful for financial support from AVL List GmbH Graz and BMW Motoren GmbH Steyr.

\section{References}

[1] Chen, J.C., A correlation for boiling heat transfer to saturated fluids in convective flow, ASME preprint 63 HT34 presented at the 6th National Heat Transfer Conference, Boston, 1963.

[2] Forster, H.K. \& Zuber N., Dynamics of vapor bubbles and boiling heat transfer, AIChE Journal, 1, pp. 531-535, 1955.

[3] Kobor, A., Entwicklung eines Siedemodells für die Simulation des kühlmittelseitigen Wärmeübergangs bei Verbrennungskraftmaschinen, Doctoral thesis, Graz University of Technology, 2003.

[4] Steiner, H., Kobor, A. \& Gebhard, L., A wall heat flux model for subcooled boiling flow, International Journal of Heat and Mass Transfer, 48, pp. 4161-4173, 2005.

[5] Kandlikar, S.G., Boiling heat transfer in binary systems: Part II - flow boiling, ASME Journal of Heat Transfer, 120, pp. 388-394, 1998.

[6] Wenzel, U. \& Müller-Steinhagen, H., Heat transfer to mixtures of acetone, isopropanol and water under subcooled flow boiling conditions - I. Experimental Results, International Journal of Heat and Mass Transfer, 37, pp. 175-184, 1994.

[7] Jakob, M. \& Fritz, W., Versuche über den Verdampfungsvorgang, Forschung auf dem des Gebiete Ingenieurwesens, 2, pp. 435-447, 1931.

[8] Bergles, A.E., The influence of heated-surface vibrations on pool boiling, ASME Journal of Heat Transfer, 91, pp. 152-153, 1969. 